\title{
A Spatiotemporal Change Detection Analysis of Coastline Data in Qingdao, East China
}

\author{
Muhammad Yasir $\left(\mathbb{D},{ }^{1}\right.$ Sheng Hui, ${ }^{2}$ Zheng Hongxia ${ }^{D},{ }^{2}$ Md Sakaouth Hossain, ${ }^{3}$ Hong Fan, ${ }^{4}$ \\ Li Zhang, ${ }^{5}$ and Zhao Jixiang ${ }^{2}$
}

${ }^{1}$ School of Geosciences, China University of Petroleum Qingdao, Qingdao 266580, China

${ }^{2}$ College of Oceanography and Space Informatics, China University of Petroleum Qingdao, Qingdao 266580, China

${ }^{3}$ Department of Geological Sciences, Jahangirnagar University, Dhaka 1342, Bangladesh

${ }^{4}$ State Key Laboratory of Information Engineering in Surveying, Mapping and Remote Sensing, Wuhan University, Wuhan 430079, China

${ }^{5}$ Key Laboratory of Digital Earth Science, Aerospace Information Research Institute, Chinese Academy of Sciences, Beijing 100094, China

Correspondence should be addressed to Zheng Hongxia; zhenghongxia@upc.edu.cn

Received 22 October 2020; Revised 24 November 2020; Accepted 8 March 2021; Published 29 March 2021

Academic Editor: Habib Ullah Khan

Copyright (c) 2021 Muhammad Yasir et al. This is an open access article distributed under the Creative Commons Attribution License, which permits unrestricted use, distribution, and reproduction in any medium, provided the original work is properly cited.

\begin{abstract}
This study focuses on the coastal features, environments, and dynamics to accurately describe and regularly monitor the Qingdao shoreline in eastern China. It collects categorical ETM+ and OLI data from 2000, 2010, and 2019 on the mainland coastline and explores the characteristics and spatiotemporal differences across the past 19 years by using remote sensing and geographic information system (GIS) technologies. The results show that the length of the Qingdao coastline has increased continuously over the last two decades, for a total increase of $18.14 \mathrm{~km}$. There are different natural and artificial coastlines that have undergone major changes. The human-induced deterioration of coastlines has gradually and substantially risen from $53.63 \%$ in 2000 to $68.40 \%$ in 2019, while the length of the natural coastlines has decreased dramatically. Jiaozhou Bay focuses on areas with significantly changing coastlines, and major changes have occurred in the west and east of the Qingdao coast. The coastline has largely expanded seaward because of the comprehensive impact of natural and anthropogenic factors. The leading factor in coastal evolution is coastal engineering constructions. In addition, the top three other construction activities are the restoration of the aquaculture pond, salt field, and harbor edifices. The driving force that triggered the shift in the coastline reveals significant temporal heterogeneity.
\end{abstract}

\section{Introduction}

The coastline makes up the border between sea and land contact [1], a significant human survival and growth base and carrier, and a special natural resource [2]. Instability [3-7], functional diversity [8], geographic disparity $[9,10]$, and other significant features are included in these characteristics. Coastal countries have converted their economic growth centers into coastal areas since the twentieth century, and almost $50 \%$ of the world's population has settled in areas within $100 \mathrm{~km}$ of the coastline [11]. More emphasis is focused on coastal changes as they are major environmental factors that directly affect coastal economic growth and land management $[12,13]$. The relocation of economic centers, however, has triggered rapid changes in coastal resources, which have had an immense effect on the economic, social, environmental, and ecological aspects of coastal areas [14]. For instance, the proportion of natural coastlines has been significantly reduced by large-scale reclamation projects [15]. The biological ecosystem of coastal areas has been degraded by the intensive use of coastlines, artificial correction of naturally curved coastlines, and disorderly aquaculture. The coastal zone has become a crucial region for coastal economic growth with the continual development 
of marine resources. An efficient way to research the environmental and ecological changes of the coastal zone is to track coastline changes. Nayak [16] suggested that, for understanding different coastal processes, detailed demarcation and monitoring of shorelines (long-term, short-term, and seasonal) are important. Coastal monitoring has therefore become an important activity for sustainable development and the conservation of the environment $[17,18]$.

Because of their high coverage and low cost, remote sensing (RS) image-based methods have now become popular for monitoring coastline changes [19-25]. Many scientists have documented changes to the coastline, and the causes of these changes have been investigated and recognized [26]. For instance, through the use of open-access multitemporal satellite imagery, Mishra et al. [27] evaluated the long-term to short-term dynamics of the coastal position of the Uri district in India over the past 25 years (1990-2015), deriving the explanation behind the changes such as human buildings and coastline erosion. Kale et al. [28] researched the erosion rates and coastal variations on the Yesilirmak River on the northern coast of Turkey before 2017 to clearly demonstrate the effect of dam buildings on the data. Thoai et al. [29] studied the changes in the coastline of the Ca Mau Cape in Vietnam over the past 20 years and concluded that forest area loss, river dredging, and aquaculture and infrastructure growth were the most significant factors influencing the changes in the coastline in the region. Wu et al. [30] took China's Shenzhen Special Economic Zone as an example to study coastline changes in the region from 1988 to 2015 and found that coastline stability characteristics were entirely different between the eastern and western coastlines of Shenzhen, with regional differences primarily reflected in morphological changes and changing coastline laws.

Researchers around the world performed their studies mainly from two viewpoints on coastline changes: (i) measuring rates of coastline shift and shifting areas of land or sea to describe coastline spatiotemporal variability [31-36]; (ii) based on a study of spatiotemporal trends of coastal changes, the exploration of the impact of geology, geomorphology, climate, and economy on coastline changes [37-40]. Many research studies on improvements to coastlines have been performed. However, the coastline derived from satellite images by several processing methods $[24,41-43]$ is the land-sea boundary that existed at the particular time of the acquisition of the image, namely, the instantaneous coastline $[44,45]$, rather than the actual geographical description of the coastline [46-48]. It is important to transform this instantaneous coastline into a tidecoordinate coastline [44]. Unless adequate ground control and photogrammetric coverage are available, this approach has restricted use for historical coastline determination [49].

In different countries, the use of remote sensing and geographic information system technologies to track changes in the coastline has become the focus of much scholarly study. The integration of the two technologies is seldom explored in many studies. The challenge of collecting data over a long-term period is one explanation for this. Other explanations are that several extraction rules have been used to extract the coastline for remote sensing details, and the extraction process is complicated. Most researchers study the coastline, or coastal region, and its driving powers. Therefore, based on five remote sensing images of Qingdao from 2000 to 2019, this study uses a visual interpretation method to extract remote sensing information of the coastline. Quantitative analysis of the Qingdao coastal long time series of different spatiotemporal evolution characteristics and response relationship is conducted. The research findings can provide basic data for the production and use of coastal protection and coastal zone and are of great importance for solving the coastal zone health ecosystem problems.

1.1. Study Area. Qingdao is in the southeast of the Shandong Peninsula, at $119^{\circ} 30^{\prime}-121^{\circ} 00^{\prime}$ east longitude, $35^{\circ} 35^{\prime}-37^{\circ} 09^{\prime}$ north latitude, bordering the Yellow Sea in the east and south, next to Yantai city in the northeast, bordering Weifang city in the west, and bordering Rizhao city in the southwest (Figure 1), a total area of $11,282 \mathrm{~km}^{2}$ [50].

\section{Materials and Methods}

2.1. Database. Landsat multitemporal satellite data (Operational Land Imager-OLI and Enhanced Thematic Mapper Plus-ETM+ sensors) with a spatial resolution of $30 \mathrm{~m}$ are used in the research work to cover the area of the study in 2000, 2010, and 2019. The images were collected from the EarthExplorer website (http://earthexplorer.usgs.gov) of the US Geological Survey (USGS), all of which were rectified and projected with a geographical error of 0.5 pixels using the Universal Transverse Mercator method in the World Reference System (WGS84) results. Table 1 depicts the details regarding the data.

\subsection{Extraction and Classification of Qingdao Coastline.} First, in this research paper, the preprocessing steps, including atmospheric correction and radiometric correction stages, have been applied to satellite images using ENVI 5.3 software. ArcGIS 10.5 was used for the classification of coastlines. The method of coastline interpretation includes visual interpretation and automated remote sensing image interpretation [51]. Methods of automatic analysis, such as the edge detection algorithm, the mathematical morphology algorithm, the region-growing algorithm, the data mining method, and the neural network method proposed in recent years, are widely used around the world, but conventional methods, such as the visual interpretation of human-computer interaction, are still widely used by experts to extract coastal information [52]. The method of human-computer integrated visual perception was therefore adopted in this article. ENVI 5.3 [53] software was used to preprocess the remote sensing images, including hypercube fast line-ofsight atmospheric analysis (FLAASH), radiometric correction, image registration, and different scene image mosaics. Most of the images were corrected systematically and geometrically. After preprocessing, the remote sensing images were separated by the normalized difference water index (NDWI) [54], the boundary line was enhanced, and the exact location of the instantaneous water edge was 


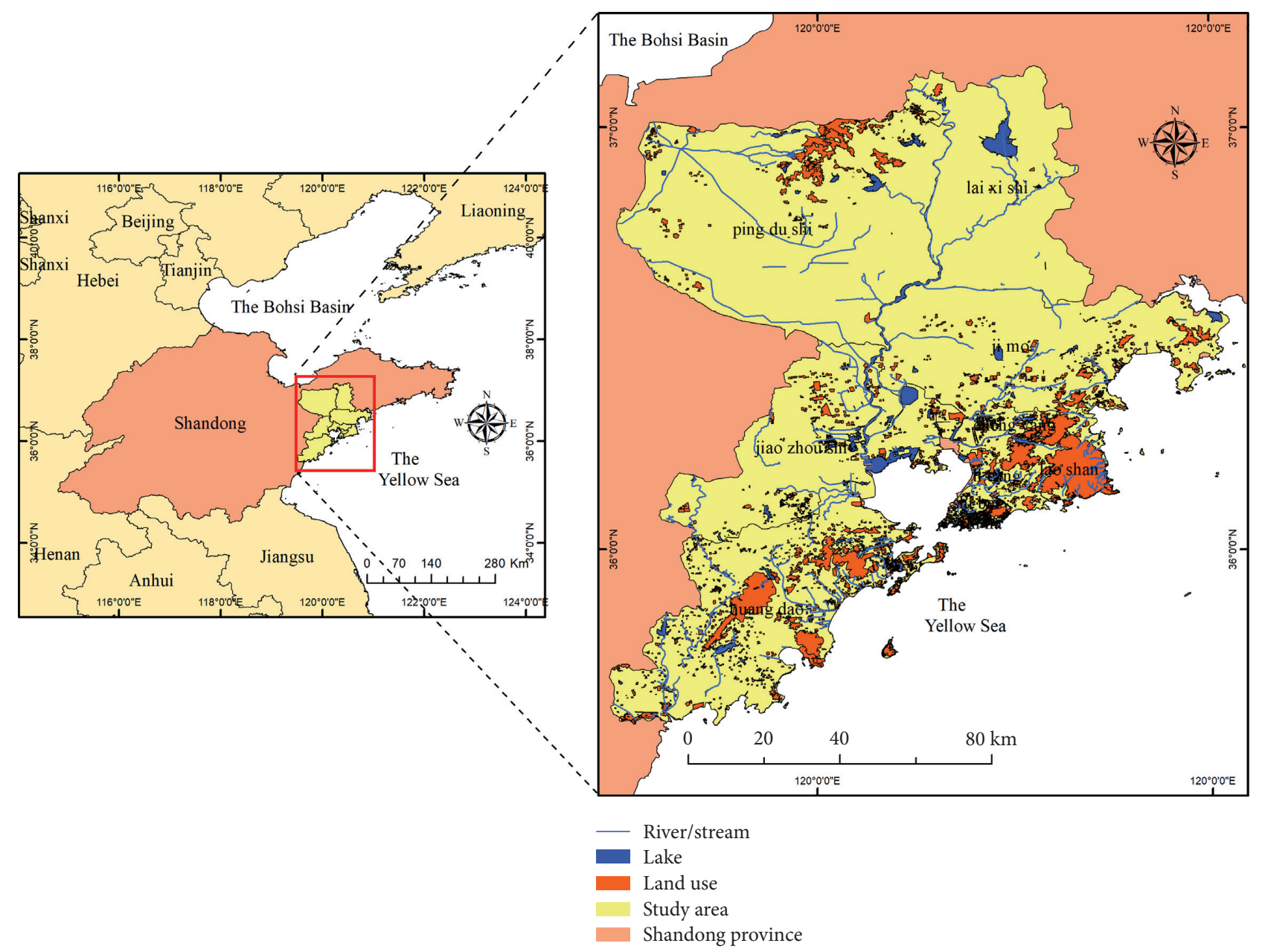

FIgURE 1: Geographical location map of Qingdao and shoreline, East China.

TABle 1: Data source and its specifications.

\begin{tabular}{lllcccccc}
\hline Year & Satellite & Sensor & Path/row & Date & Resolution $(\mathrm{m})$ & Cloud & No. of bands & Format \\
\hline 2000 & Landsat_7 & ETM+ & $120 / 35$ & $08 / 9 / 2000$ & 30 & 0 & 7 & Geo TIF \\
2010 & Landsat_7 & ETM+ & $120 / 35$ & $29 / 10 / 2010$ & 30 & 0 & 7 & Geo TIF \\
2019 & Landsat_8 & OLI & $120 / 35$ & $29 / 9 / 2019$ & 30 & 0 & 11 & Geo TIF \\
\hline
\end{tabular}

obtained by Otsu's threshold segmentation method based on the clarification of the characteristics of the differential reflection spectrum near the coastline [55]. The classification of the coastline acquired was mainly based on information gained from Google Earth images and field surveys; subsequently, topographical map digitization and visual analysis of remote sensing images were categorized. The coastlines were divided into coastlines on the island and coastlines on the mainland, and we only examined the mainland coastlines in this article.

2.3. Accuracy Validation of Extracted Coastlines. To test the accuracy of the extracted coastline, the statistical method of manually choosing random points was used [56]. First, on the initial image along the edge of the coastline, we manually picked 900 points. For each data cycle, we selected 900 points, for 2700 points for accuracy evaluation. Then, from each random point to the extracted coastline, we determined the shortest distance. The distance value was positive if the random point was within the land; otherwise, it was negative. The image resolution of TM/ETM+ and OLI was $30 \mathrm{~m}$ (Table 1). Therefore, according to the statistical results of the histogram (Figure 2), the proportions of random points chosen in 2000 within a one-pixel distance were $87.55 \%$ in the three cycles of 2000, 2010, and 2019, 90.78\% in 2010 within a one-pixel distance, and $94.45 \%$ in 2019 within a one-pixel distance, and the extraction results were satisfactory.

\section{Results}

3.1. Classification of Coastlines. The distribution of coastal types for the years 2000, 2010, and 2019 was obtained through the acquisition and subsequent analysis of images of 


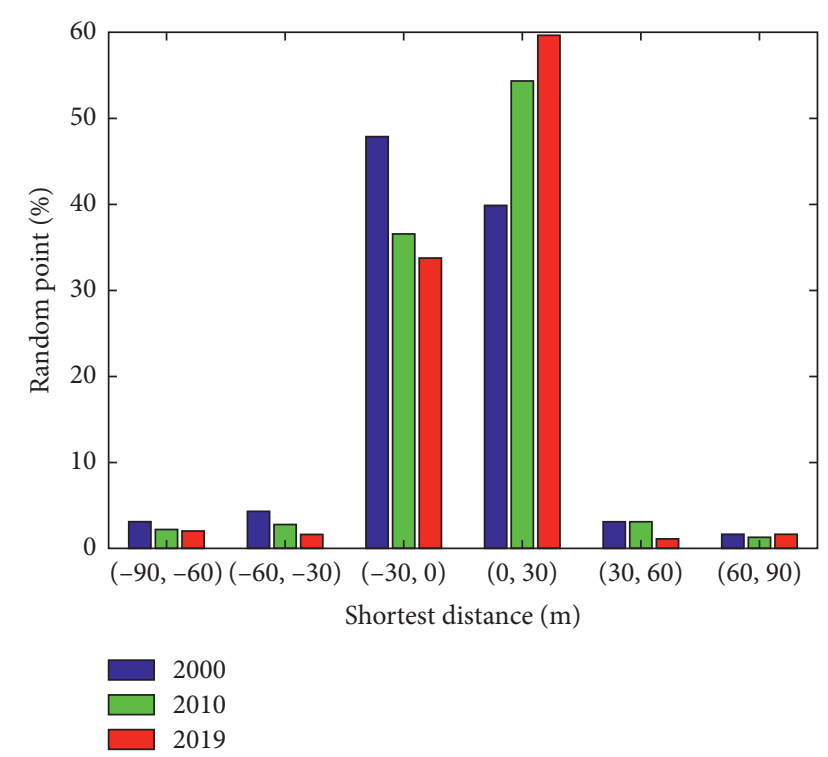

Figure 2: Histogram of randomly selected reference points (\%) and the shortest distances $(\mathrm{m})$ to the extracted coastlines.

the coastal areas of Qingdao covered by remote sensing satellites over the past 19 years. The Qingdao coastline was split into natural coastlines and artificial coastlines based on detailed research findings [3,57-60]. The natural coastlines were divided into bedrock coastline, sandy coastline, muddy coastline, and estuaries; furthermore, the artificial coastlines were divided into harbor and wharf, revetment and seawall, aquaculture, and salt field. On the Landsat images, the corresponding coastline was shown in 543, 432, and 321 bands combined with false color displays (Figure 3), and finally, the coastline classification was achieved through interactive visual representation between humans and computers. Detailed classification information is shown in Table 2.

According to the statistics of the coastline classification results shown in Table 3 and Figure 4 the total length of Qingdao's coastline in 2000 was $507 \mathrm{~km}$, of which the total length of the natural coastline was $235.22 \mathrm{~km}$, and the total length of the artificial coastline was $272.34 \mathrm{~km}$. As shown in Table 3, from 2000 to 2019, because of the comprehensive effects of natural and anthropogenic factors, the total length of coastlines in Qingdao increased by $4.35 \%$ in which the rates of change in 2000-2010 and 2010-2019 were 2.01 and 2.29 , respectively, with a trend of accelerating growth. Anthropogenic variables influenced the coastline of Qingdao from 2000 to 2019. The total length of artificial coastlines increased from $272.34 \mathrm{~km}$ in 2000 , accounting for $53.63 \%$ of the total length of the coastline, to $359.81 \mathrm{~km}$ in 2019 , accounting for $68.40 \%$ of the coastline (Figure $4(\mathrm{a})$ ).

The length of the natural boundary lines quickly decreased from $235.52 \mathrm{~km}$ to $180.15 \mathrm{~km}$ and then decreased steadily to $166.19 \mathrm{~km}$. On the opposite, the length of the artificial boundary line grew quickly at first and then increased steadily. In 2019, its size grew to $526 \mathrm{~km}$ from $507.86 \mathrm{~km}$ in 2000. Throughout the long coastal region of Qingdao, bedrock has continuously deteriorated along the natural coastline
(Figure 5). From 2000 to 2019, the bedrock coastline was substantially reduced from $29.04 \%$ to $13.65 \%$ by proportion. The sandy and estuarine coastline types have probably shown a growing pattern from 2000 to 2019 over the entire period. The muddy coastline was the only form of coastline where no change was observed overall. The largest altered portion among the artificial coastlines was aquaculture, followed by revetment and seawall (Figure 5). The area of the aquaculture coastline grew steadily over the entire period from 2000 to 2010, but its length decreased between 2010 and 2019. In the entire time from 2000 to 2019, harbor and wharf have progressed along the entire coastline. The salt field was the only coastline that proportionally showed a declining trend in its duration from 2000 to 2019 , and it was $7.43 \%$ to $4.64 \%$. Construction showed a decreasing trend from 2000 to 2010, but it increased rapidly after 2010. Despite the fact that the seawall and revetment only cover a small portion of the total coastline, their growth rate accelerated after 2000, and they were particularly visible from 2010 to 2019. In Figure 5, the spatial distributions are shown.

\section{Discussion}

A complicated interaction of different human-induced and natural coastal processes triggers the shoreline changes. The shorelines are changed by natural processes because of geology and geomorphology, the cumulative motion of tides and winds, sea level fluctuations, tectonics, and storms. Manipulation of hydrological cycles by dam construction, building on beaches, coastal structures such as harbors, beach-protecting structures, jetties, mining of beach sand, and degradation of coastal vegetation are the human activities that could exacerbate coastal changes. Most of the anthropogenic growth was the key reason for the coastline change in Qingdao over 19 years, while the natural factors were the secondary reasons [50]. The overall changes of shorelines along the coast of mainland China increased over the $1990-2019$ period primarily for land reclamation and quay construction [61].

Climatic conditions and natural processes are important in determining shoreline changes. These processes are influenced not only by changes in tides, waves, etc., on an hourly or daily basis but also over longer timescales, such as sea level and climate change. Relative sea level rise, which may occur because of a rise in the water volume of the seas or the subsidence or emergence of land by natural processes, is a long-term geological phenomenon of paramount significance to the shoreline. In the Qingdao coastal zone, the relative change in the sea level might be involved in modifying the shorelines. Over the past decades, the length of natural shorelines of each subtype has decreased, while artificial construction and quay shorelines of the artificial group have increased dramatically [61].

The shoreline changes have included different coastal landform features such as headland and bays, mudflats, estuaries, beaches, and bedrocks in the study area. The present study shows that the coastal areas of the bedrocks are under significant threat of decline. More changes have occurred in the narrow continental shelf and exposed rocky 


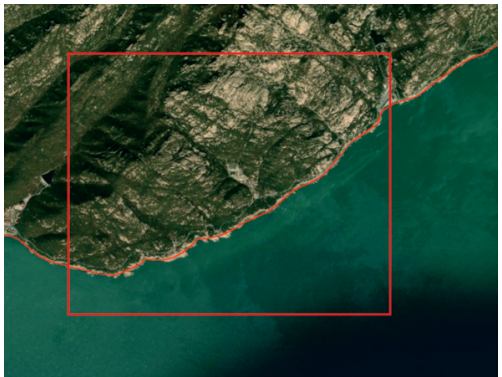

(a)

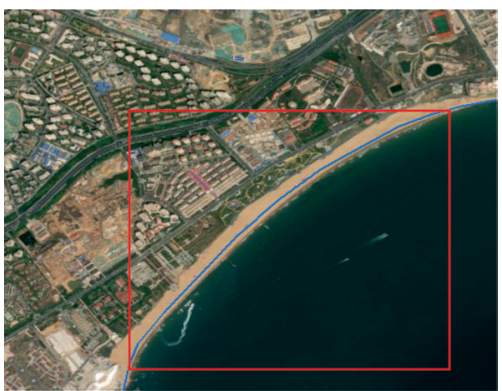

(c)

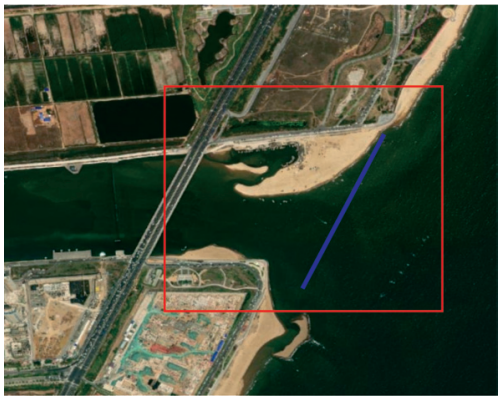

(e)

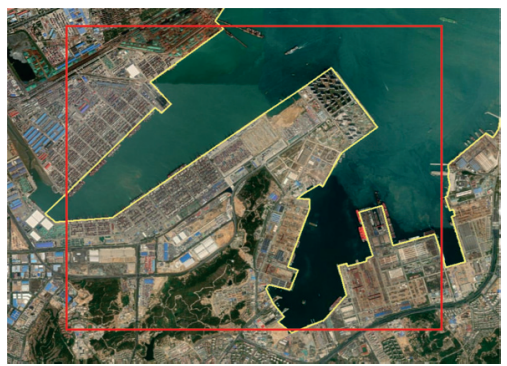

(g)

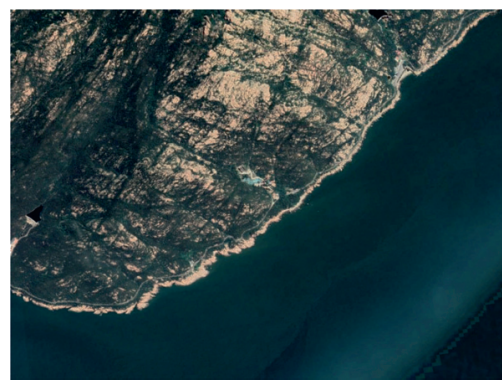

(b)

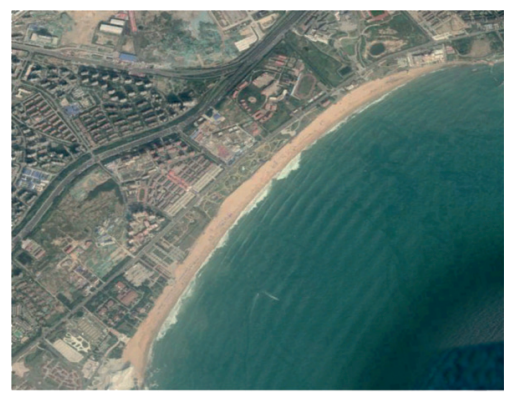

(d)

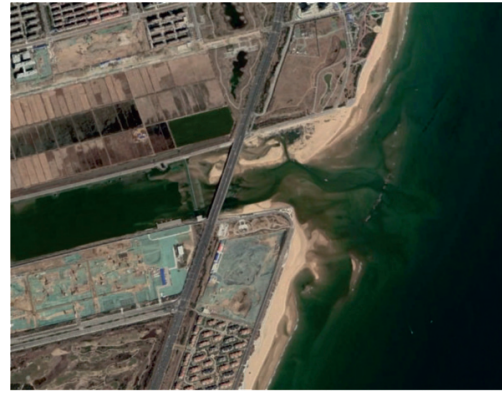

(f)

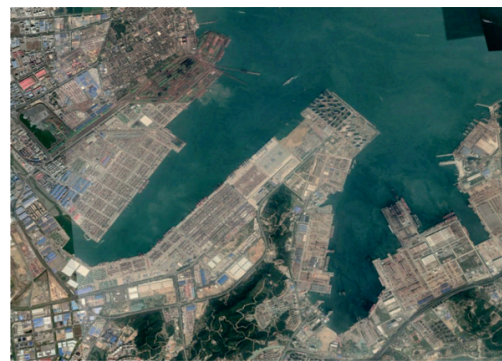

(h)

- Artificial coastline

— Bedrock coastline

_ Estuarine coastline

FiguRE 3: Rocky coastline (a, b), sandy coastline (c, d), estuarine coastline (e, f), and artificial coastline (g, h) superimposed on Landsat (2019) and Google Earth images (2019).

coast regions, resulting in the accumulation of sandy and muddy sediments along beaches and estuaries. More sediments are produced, and cliffs are created by the high wave energy acting on the soft part of the bedrocks, which eventually changes the shoreline along the entire study area.

In the present results, rocky shorelines were lost, which evinces how anthropogenic changes that are often extreme to local ecosystems will destroy natural environments and prevent the accessibility of future generations from experiencing these lively, living landscapes. Sand deposited along the beaches is for the influence of materials transported by continental rivers and waves [62]. Coastal shifts have also been witnessed by low-lying sandy beaches and dunes, resulting in an overall seaward rise along the shoreline. The 
TABLE 2: The coastline classification system of Qingdao, East China.

\begin{tabular}{|c|c|c|c|}
\hline $\begin{array}{l}\text { Primary } \\
\text { categories }\end{array}$ & Secondary categories & Classification definition & $\begin{array}{l}\text { Location } \\
\text { name }\end{array}$ \\
\hline \multirow{4}{*}{ Natural } & Bedrock boundary line & $\begin{array}{l}\text { It is the demarcation line on the bedrock coast between } \\
\text { the land and sea }\end{array}$ & Liuqinghe \\
\hline & Estuary boundary line & $\begin{array}{l}\text { The border between the ocean and the estuary and between } \\
\text { the ocean and the river }\end{array}$ & Mengjiatan \\
\hline & Sandy boundary line & $\begin{array}{c}\text { Composed of loose, very soft, and fine materials such as sand, silt, } \\
\text { and sludge; comprising relatively straight coastline and wide, long } \\
\text { beaches; sand in the bay at high tide }\end{array}$ & Jinshatan \\
\hline & Muddy boundary line & $\begin{array}{l}\text { Coastline on the muddy or silt coast, which is usually at the } \\
\text { vegetation line where salt-tolerant plant distribution patterns change }\end{array}$ & Wangtai \\
\hline \multirow{6}{*}{ Artificial } & Salt field boundary line & The saline-alkali drying sea-land dividing line & Taitou \\
\hline & Construction boundary line & $\begin{array}{c}\text { A land-to-sea demarcation line for the growth of the maritime } \\
\text { industry and for other constructions }\end{array}$ & Suliu \\
\hline & Harbor and wharf boundary line & $\begin{array}{c}\text { A demarcation line for the practical usage of port terminals } \\
\text { between the land and sea }\end{array}$ & Xiangyang \\
\hline & Breeding boundary line & An artificially built land-sea border for aquaculture & Yinghai \\
\hline & Road boundary line & The land-sea dividing line of the artificially built highway & Xiaozhuang \\
\hline & Other artificial boundary lines & $\begin{array}{c}\text { Lines of artificial boundaries, which do not belong to the } \\
\text { classification above }\end{array}$ & \\
\hline
\end{tabular}

Table 3: Qingdao coastline statistics for 2000, 2010, and 2019.

\begin{tabular}{|c|c|c|c|c|c|c|c|c|}
\hline \multirow{2}{*}{ Coastline types } & \multicolumn{2}{|c|}{2000} & \multicolumn{2}{|c|}{2010} & \multicolumn{2}{|c|}{2019} & \multicolumn{2}{|c|}{ Net change area $(\%)$} \\
\hline & Area $(\mathrm{km})$ & Area $(\%)$ & Area $(\mathrm{km})$ & Area (\%) & Area $(\mathrm{km})$ & Area (\%) & 2000-2010 & 2010-2019 \\
\hline \multicolumn{9}{|l|}{ Natural coastline } \\
\hline Bed rock & 147.49 & 29.04 & 86.55 & 16.70 & 72.35 & 13.65 & 12.34 & 3.05 \\
\hline Sandy & 80.64 & 15.87 & 88.15 & 17.01 & 88.74 & 16.74 & 1.14 & 0.27 \\
\hline Muddy & 3.81 & 0.75 & - & - & - & - & - & - \\
\hline Estuary & 3.58 & 0.70 & 5.45 & 1.05 & 5.10 & 0.96 & 0.35 & 0.09 \\
\hline Subtotal & 235.52 & 46.37 & 180.15 & 34.77 & 166.19 & 31.35 & 11.6 & 3.42 \\
\hline \multicolumn{9}{|l|}{ Artificial coastline } \\
\hline Aquaculture & 117.19 & 23.07 & 167.01 & 32.23 & 137.29 & 26.08 & 9.16 & 6.15 \\
\hline Salt field & 37.76 & 7.43 & 31.87 & 6.15 & 24.51 & 4.62 & 1.28 & 1.53 \\
\hline Construction & 21.82 & 4.29 & 16.87 & 3.25 & 35.71 & 6.92 & 1.04 & 3.67 \\
\hline Harbor and wharf & 31.34 & 6.17 & 55.72 & 10.75 & 66.18 & 12.67 & 4.58 & 1.92 \\
\hline Revetment and seawall & 64.25 & 12.65 & 66.46 & 12.82 & 96.12 & 18.32 & 0.17 & 5.5 \\
\hline Subtotal & 272.34 & 53.63 & 337.93 & 65.23 & 359.81 & 68.65 & 11.6 & 3.42 \\
\hline Total & 507.86 & 100 & 518.08 & 100 & 526.00 & 100 & - & - \\
\hline
\end{tabular}

Qingdao coastal zone has headlands and bays, which result in changes in the shoreline along the coast. There are few areas with curved sandy beaches and multiple estuaries that easily trap the sediments and contribute to the shoreline changes. Coastal plains are often formed depending on the rivers and their catchment area [63]. Development and its associated sedimentary processes have been and are some principal contributors to coastal geomorphology in much of the coastal region. The deposition of sediment shapes coastal features such as beaches, mudflats, estuaries, mangroves, and sand dunes. During 2000-2019, the Qingdao coastal region has experienced more accretion for the excess amount of sediment discharged through the rivers [47]. Sediment discharges from rivers are considerably reduced due to the building of dams, infrastructures, development activities, and encroachments (Figure 3 ). This makes the sandy beaches along the shoreline more vulnerable to destruction.
Ocean waves are one of the prime movers for the littoral processes which bring changes along the shoreline. For example, the greatest factor affecting the evolution of the shoreline shift is the long-shore sediment transport rate [64]. In the formation of such coastal features, such as bars and spits, coastal transport plays a major role and causes substantial shoreline changes [65]. The coastal zones of Qingdao have experienced changes because of the littoral drift of sediments transported through the Yang, Feng, Long Quan, and $\mathrm{Wu}$ Long Rivers. Most of the rivers have failed to develop true deltaic characteristics because of the strong offshore current in the study area.

Human interventions and anthropogenic activities have a major influence on shifts in shorelines. Consistent with previous researchers $[3,66]$, the key driving force behind the shoreline changes was human activities, including land reclamation [67-69], aquaculture development [60], and 


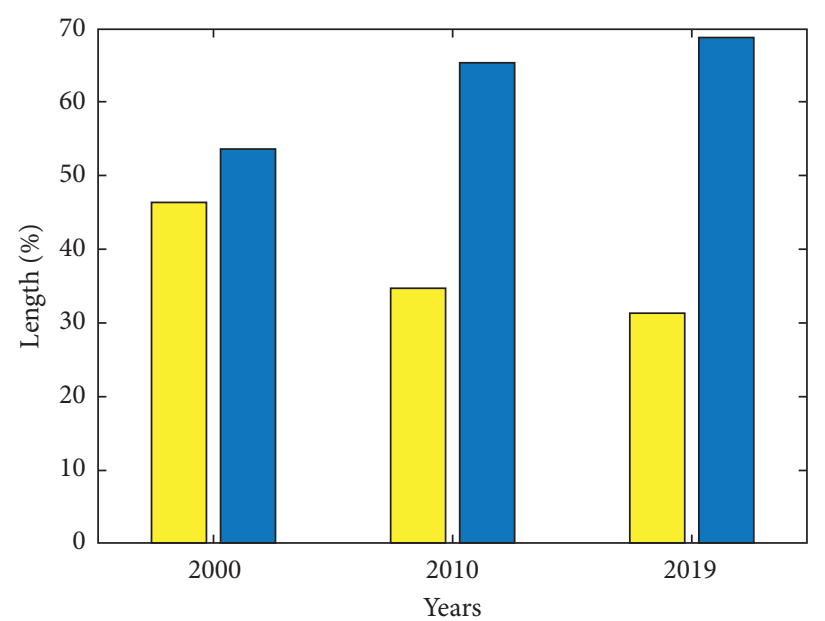

Natural Artifical

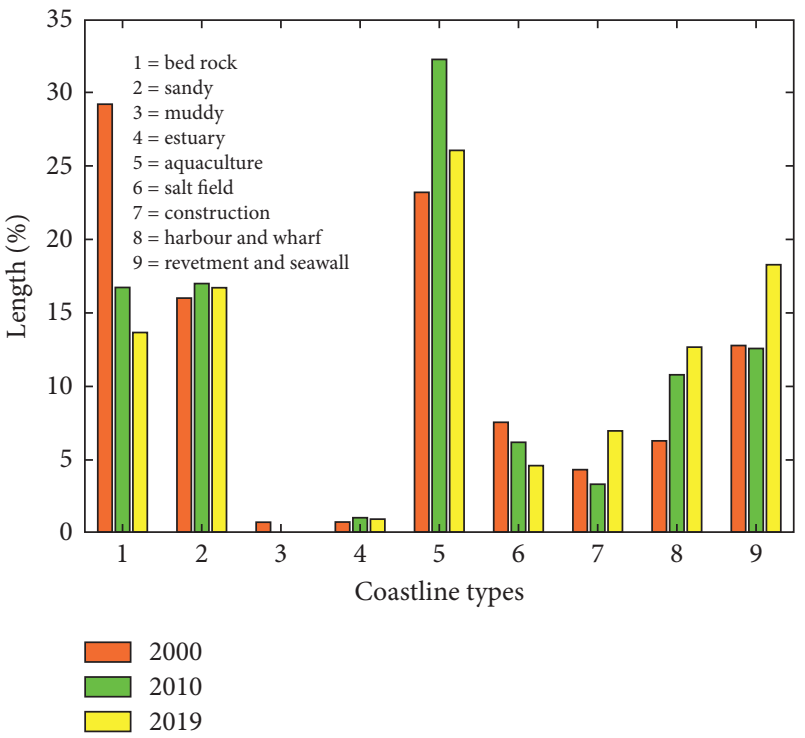

(b)

FigURE 4: (a) Artificial and natural coastline length (\%) from 2000 to 2019 and (b) percentage of different coastline lengths from 2000 to 2019 of Qingdao coast.
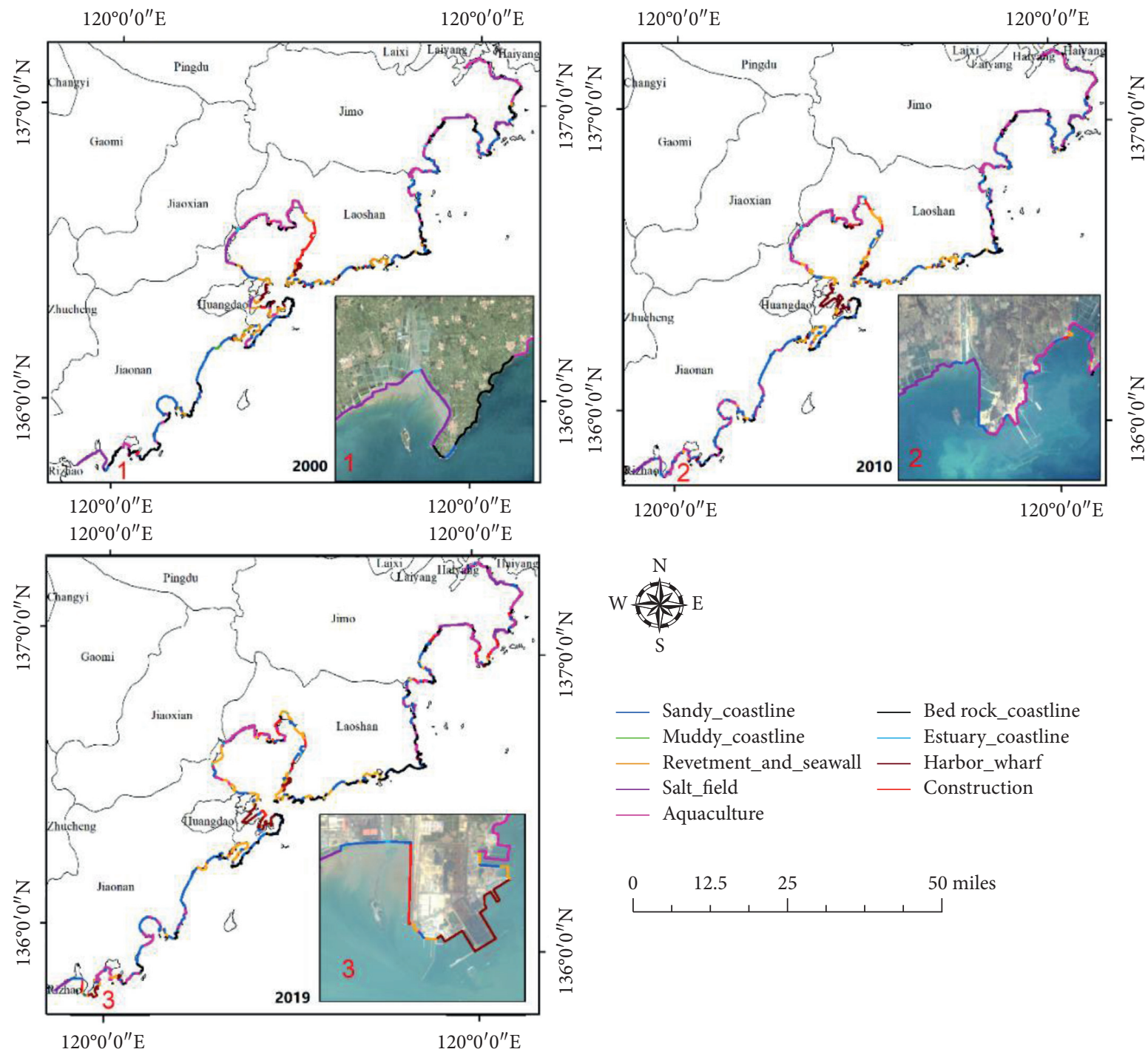

FIgURE 5: The spatial distribution on the Qingdao coast of the secondary coastlines. 
quay construction [70]. The shoreline morphology also results in coastal urbanization, extraction, shifting of coastal sands, and dredging. The reduced supply of sediment caused by offshore sand mining, shoreline disturbances, and damming of sediment-rich rivers has led to the further loss and deterioration of coastal ecosystems, including beaches, estuaries, and mudflats.

The construction of coastal structures such as seawall, revetment, harbors, wharf, and aquaculture in Qingdao coastal regions may interfere with the process of long-shore drift, changing the sediment budget and exacerbating shoreline changes of the adjacent bedrocks, estuaries, mudflats, beaches, or beach head in a down-drift direction. The current study shows that, for anthropogenic processes along the coast, the Qingdao coast undergoes greater changes. Shoreline changes are exacerbated by unsustainable coastal construction programs. Different construction works are carried out along the shore that can cause major changes in the surrounding shoreline coastal area. The present studied coast of Qingdao is heavily experienced by constructions, revetment, seawall, and aquacultural activities (Figures 3(g) and 3(h)). Because of anthropogenic activities, this coast has high change rates, and it discloses the fact that the existence of river input, salt fields, and wave patterns determines the rate of shoreline changes. The disruption of river input is apparent here, which results in the beach's direct risk of survival.

There are several factors such as sand dunes and vegetation which protect shorelines from changes and help to preserve the coastal environment. The human-induced activities that cause shoreline changes have significantly affected these natural protections. Tian et al. [61] mentioned in 2020 that low-economic value shorelines, such as rocky, sandy, muddy, and estuarine shorelines, were transformed into high-economic value shorelines, such as aquaculture, which were transformed into shorelines with even more economic values, such as shorelines of construction and quay. Growing populations and development works along the coasts put the coastal ecosystems under unprecedented pressure. Meanwhile, ongoing manifestations of climate change, such as increasing sea levels and the severity of storm surges, increase the threats to the coastal population's habitats, natural resources, infrastructure, and well-being.

\section{Conclusion}

In this study, Landsat ETM+ images for 2000 and 2010 and Landsat OLI images for 2019 are used to delineate and classify the coastline along the East China coast of Qingdao. Because of both natural and human-induced activities, the Qingdao coastal zone has undergone significant coastline modifications. The spatial and temporal variations of the coastline in the study area have been extensive in the past 19 years: the length of the coastline has increased substantially from 2000 to 2019. The increased types of coastline are predominantly artificial frontier lines. The current study shows that the total length of artificial coastlines grew from $272.34 \mathrm{~km}$ in 2000 , representing $53.63 \%$ of the total length of the coastline, to $359.79 \mathrm{~km}$ in 2019 , representing $68.40 \%$ of the coastline. The rocky coast of the natural coastline decreased dramatically from $29.04 \%$ to $13.65 \%$ by proportion, whereas the largest portion covered by aquaculture in the artificial coastline changed from $23.07 \%$ in 2000 to $26.08 \%$ in 2019.

The growth of the coastline has been significantly influenced by human activities. The length of the natural coastal boundary line has deteriorated, converting a substantial number of natural coastlines into artificial coastlines. The geomorphological and geological effects, sediment supply, and relative increase in sea level promote shoreline development. The analysis of the shoreline change rate often shows both short- and long-term changes along the studied area's different coastal zones. Eventually, the environmental and resource shifts of the studied Qingdao coastal zone influence the coastal landforms. The types of coastal landforms change with the changes in the artificial and natural features along the coastline, particularly the infrastructure, aquaculture, harbor structures, bedrocks, beaches, estuaries, and mudflats. Human activities influence not only the shifts in the coastline but also the coastal zone's types and areas of surface coverage. A realistic management method is provided by the study of shoreline change and modes based on geomorphic concepts and thus understanding the reasons for shoreline changes. The present research thus clearly focuses on the impacts of the coastal processes produced in the study area, both natural and anthropogenic.

\section{Data Availability}

The authors used the USGS and field data along Qingdao coastline.

\section{Conflicts of Interest}

The authors declare that they have no conflicts of interest.

\section{Acknowledgments}

This work was supported in part by the National Key Research and Development Program (Grant no. 2017YFC145600) and the National Natural Science Foundation of China (Grant no. 41776182).

\section{References}

[1] P. S. Mujabar and N. Chandrasekar, "Shoreline change analysis along the coast between Kanyakumari and Tuticorin of India using remote sensing and GIS," Arabian Journal of Geosciences, vol. 6, no. 3, pp. 647-664, 2011.

[2] X. Huang, Resource Economics, Vol. 1-3, Nanjing University Press, Nanjing, China, 2010.

[3] X. Hou, J. Liu, Y. Song, and X. Li, "Environmental-ecological effect of development and utilization of China's coastline and policy recommendations," Bulletin China Academy Science, vol. 31, pp. 1143-1150, 2016.

[4] C. Salmon, V. K. E. Duvat, and V. Laurent, "Human- and climate-driven shoreline changes on a remote mountainous tropical Pacific Island: tubuai, French Polynesia," Anthropocene, vol. 25, Article ID 100191, 2019. 
[5] J. H. List, A. S. Farris, and C. Sullivan, "Reversing storm hotspots on sandy beaches: spatial and temporal characteristics," Marine Geology, vol. 226, no. 3-4, pp. 261-279, 2006.

[6] Z. Umar, W. A. A. W. M. Akib, and A. Ahmad, "Monitoring shoreline change using Remote sensing and GIS: a case study of padang coastal area, Indonesia," in Proceedings of the IEEE 9th International Colloquium on Signal Processing and its Applications, pp. 280-284, Kuala Lumpur, Malaysia, March 2013.

[7] R. Ranasinghe, T. M. Duong, S. Uhlenbrook, D. Roelvink, and M. Stive, "Climate-change impact assessment for inletinterrupted coastlines," Nature Climate Change, vol. 3, no. 1, pp. 83-87, 2012.

[8] T. Liao, T. Cai, Y. Liu, and X. Xia, "Continental shoreline change in Zhejiang during the last one hundred years," Journal of Marine Science, vol. 34, pp. 25-33, 2016.

[9] B. Wang, L. Liang, F. Hui et al., "Spatiotemporal changes of the Chinese coastlines: landsat imagery from 1975 to 2015," Journal of Beijing Normal University (Natural Science), vol. 55, pp. 83-100, 2019.

[10] X. Sun, M. Wu, J. Tian et al., "Driving forces and spatiotemporal variation of Weihai coastline in recent 30 years," Journal of Oceanography, vol. 38, pp. 206-213, 2019.

[11] J. Li, M. Ye, R. Pu et al., "Spatiotemporal change patterns of coastlines in zhejiang province, China, over the last twentyfive years," Sustainability, vol. 10, no. 2, p. 477, 2018.

[12] R. Welch, M. Remillard, and J. Alberts, "Integration of GPS, remote sensing, and GIS techniques for coastal resource management," Photogrammetric Engineering and Remote Sensing, vol. 58, pp. 1571-1578, 1992.

[13] H. Stokkom, G. Stokman, and J. Hovenier, "Quantitative use of passive optical remote sensing over coastal and inland water bodies," International Journal of Remote Sensing, vol. 14, pp. 541-563, 1993.

[14] A. D. Switzer, C. R. Sloss, B. P. Horton, and Y. Zong, "Preparing for coastal change," Quaternary Science Reviews, vol. 54, pp. 1-3, 2012.

[15] Y. Yan, Z. Zhang, C. Wang, L. Zhang, Y. Huang, and J. Zhang, "Analysis of recent coastline evolution due to marine reclamation projects in the Qinzhou Bay," Polish Maritime Research, vol. 24, no. s2, pp. 188-194, 2017.

[16] S. R. Nayak, "Use of satellite data in coastal mapping," Indian Cartographer, vol. 23, pp. 147-157, 2002.

[17] E. Sener, A. Davraz, and S. Sener, "Investigation of aksehir and eber lakes (SW Turkey) coastline change with multitemporal satellite images," Water Resources Management, vol. 24, no. 4, pp. 727-745, 2009.

[18] G. Zhu and $\mathrm{X}$. Xu, "Annual processes of land reclamation from the sea along the northwest coast of bohai bay during 1974 to 2010," Journal of Geographical Sciences, vol. 32, pp. 1006-1012, 2012.

[19] A. A. Alesheikh, A. Ghorbanali, and N. Nouri, "Coastline change detection using remote sensing," International Journal of Environmental Science \& Technology, vol. 4, no. 1, pp. 61-66, 2007.

[20] L. J. Moore, "Shoreline mapping techniques," Journal of Coastal Research, vol. 16, pp. 111-124, 2000.

[21] A. Saleem and J. L. Awange, "Coastline shift analysis in data deficient regions: exploiting the high spatio-temporal resolution Sentinel-2 products," Catena, vol. 179, pp. 6-19, 2019.

[22] K. Nassar, H. Fath, W. E. Mahmod, A. Masria, K. Nadaoka, and A. Negm, "Automatic detection of shoreline change: case of North Sinai coast, Egypt," Journal of Coastal Conservation, vol. 22, no. 6, pp. 1057-1083, 2018.
[23] B. Pradhan, H. Rizeei, and A. Abdulle, "Quantitative assessment for detection and monitoring of coastline dynamics with temporal RADARSAT images," Remote Sensing, vol. 10, no. 11, Article ID 1705, 2018.

[24] H. Liu and K. C. Jezek, "Automated extraction of coastline from satellite imagery by integrating canny edge detection and locally adaptive thresholding methods," International Journal of Remote Sensing, vol. 25, no. 5, pp. 937-958, 2004.

[25] B.-J. He, Z.-Q. Zhao, L.-D. Shen, H.-B. Wang, L.-G. Li, and B.-J. He, "An approach to examining performances of cool/ hot sources in mitigating/enhancing land surface temperature under different temperature backgrounds based on Landsat 8 image," Sustainable Cities and Society, vol. 44, pp. 416-427, 2019.

[26] X. Li and M. C. J. Damen, "Coastline change detection with satellite remote sensing for environmental management of the Pearl River Estuary, China," Journal of Marine Systems, vol. 82, pp. S54-S61, 2010.

[27] M. Mishra, P. Chand, N. Pattnaik et al., "Response of long- to short-term changes of the Puri coastline of Odisha (India) to natural and anthropogenic factors: a remote sensing and statistical assessment," Environmental Earth Sciences, vol. 78, p. 338, 2019.

[28] M. M. Kale, M. Ataol, and I. S. Tekkanat, "Assessment of shoreline alterations using a Digital Shoreline Analysis System: a case study of changes in the Ye, silırmak Delta in northern Turkey from 1953 to 2017," Environmental Monitoring and Assessment, vol. 191, p. 398, 2019.

[29] D. T. Thoai, A. N. Dang, and N. T. Kim Oanh, "Analysis of coastline change in relation to meteorological conditions and human activities in Ca mau cape, Viet Nam," Ocean \& Coastal Management, vol. 171, pp. 56-65, 2019.

[30] X. Wu, C. Liu, and G. Wu, "Spatial-temporal analysis and stability investigation of coastline changes: a case study in shenzhen, China," Institute of Electrical and Electronics Engineers Journal of Selected Topics in Applied Earth Observations and Remote Sensing, vol. 11, no. 1, pp. 45-56, 2018.

[31] S. R. Ahmad and V. C. Lakhan, "GIS-based analysis and modeling of coastline Advance and retreat along the coast of Guyana," Marine Geodesy, vol. 35, Article ID 1e15, 2012.

[32] R. Dolan, B. Hayden, and J. Heywoode, "A new photogrammetric method for determining coastline erosion," Coastal Engineering, vol. 2, Article ID 21e39, 1978.

[33] T. Kuleli, "Quantitative analysis of coastline changes at the Mediterranean Coast in Turkey," Environmental Monitoring and Assessment, vol. 167, Article ID 387e397, 2010.

[34] T. Kuleli, A. Guneroglu, K. Fevzi, and M. Dihkan, "Automatic detection of coastline change on coastal Ramsar wetlands of Turkey," Ocean Engineering, vol. 38, Article ID 1141e1149, 2011.

[35] J. M. Kusimi and J. L. Dika, "Sea erosion at Ada Foah: assessment of impacts and proposed mitigation measures," Natural Hazards, vol. 64, Article ID 983e997, 2012.

[36] M. L. Yates, G. L. Cozannet, M. Garcin, E. Salai, and P. Walker, "Multidecadal atoll coastline change on manihi and manuae, French polynesia," Journal of Coastal Research, vol. 29, Article ID 870e882, 2013.

[37] S. S. Durduran, "Coastline change assessment on water reservoirs located in the Konya Basin Area, Turkey, using multitemporal landsat imagery," Environmental Monitoring and Assessment, vol. 164, Article ID 453e461, 2010.

[38] S. Quan, R. G. Kvitek, D. P. Smith, and G. B. Griggs, "Using vessel-based LIDAR to quantify coastal erosion during El $\mathrm{Ni} \sim$ no and inter-El $\mathrm{Ni} \sim$ no periods in Monterey Bay, 
California," Journal of Coastal Research, vol. 29, Article ID 555e565, 2013.

[39] S. M. Solomon, "Spatial and temporal variability of coastline change in the Beaufort-Mackenzie region, northwest territories, Canada," Geo-Marine Letters, vol. 25, Article ID 127e137, 2005.

[40] D. C. Twichell, J. G. Flocks, E. A. Pendleton, and W. E. Baldwin, "Geologic controls on regional and local erosion rates of three northern Gulf of Mexico Barrier-Island systems," Journal of Coastal Research, vol. 63, Article ID 32e $45,2013$.

[41] J. S. Lee and I. Jurkevich, "Coastline detection and tracing in SAR images," Institute of Electrical and Electronics Engineers Transactions on Geoscience \& Remote, vol. 28, no. 4, pp. 662-668, 1990.

[42] J. Ryu, J. Won, and K. Min, "Waterline extraction from Landsat TM data in a tidal flatA case study in Gomso Bay, Korea," Remote Sensing of Environment, vol. 83, no. 3, pp. 442-456, 2002.

[43] D.-J. Kim, W. M. Moon, S.-E. Park, J.-E. Kim, and H.-S. Lee, "Dependence of waterline mapping on radar frequency used for sar images in intertidal areas," Institute of Electrical and Electronics Engineers Geoscience and Remote Sensing Letters, vol. 4, no. 2, pp. 269-273, 2007.

[44] R. Li, R. Ma, and K. Di, "Digital tide-coordinated shoreline," Marine Geodesy, vol. 25, no. 1-2, pp. 27-36, 2002.

[45] A. M. Muslim and G. M. Foody, "DEM and bathymetry estimation for mapping a tide-coordinated shoreline from fine spatial resolution satellite sensor imagery," International Journal of Remote Sensing, vol. 29, no. 15, pp. 4515-4536, 2008.

[46] E. H. Boak and I. L. Turner, "Shoreline definition and detection: a review," Journal of Coastal Research, vol. 214, no. 4, pp. 688-703, 2005.

[47] X. F. Ma, D. Z. Zhao, X. G. Xing, F. S. Zhang, S. Y. Wen, and F. Yang, "Means of withdrawing coastline by remote sensing," Marine Environmental Research, vol. 26, no. 2, pp. 185-189, 2007, in Chinese.

[48] J. Xu, Z. Zhang, X. Zhao et al., "Spatial and temporal variations of coastlines in northern China (2000-2012)," Journal of Geographical Sciences, vol. 24, no. 1, pp. 18-32, 2014.

[49] R. Gens, "Remote sensing of coastlines: detection, extraction and monitoring," International Journal of Remote Sensing, vol. 31, no. 7, pp. 1819-1836, 2010.

[50] M. Yasir, H. Sheng, H. Fan et al., "Automatic coastline extraction and changes analysis using remote sensing and GIS technology," Institute of Electrical and Electronics Engineers Access, vol. 8, pp. 180156-180170, 2020.

[51] X. Ma, "An overview of means of withdrawing coastline by remote sensing," Remote Sensing Technology and Application, vol. 22, no. 4, pp. 575-580, 2007.

[52] M. Zhou, M. Wu, G. Zhang, L. Zhao, X. Hou, and Y. Yang, "Analysis of coastal zone data of northern Yantai collected by remote sensing from 1990 to 2018," Applied Sciences, vol. 9, no. 20, p. 4466, 2019.

[53] S. Deng, ENVI Remote Sensing Image Processing Method, Higher Education Press, Beijing, China, 2014.

[54] S. K. McFeeters, "The use of the Normalized Difference Water Index (NDWI) in the delineation of open water features," International Journal of Remote Sensing, vol. 17, no. 7, pp. 1425-1432, 1996.

[55] N. Otsu, "A threshold selection method from gray-level histograms," Institute of Electrical and Electronics Engineers
Transactions on Systems, Man, and Cybernetics, vol. 9, no. 1, pp. 62-66, 1979.

[56] X. Ge, X. Sun, and Z. Liu, "Objectriented coastline classification and extraction from remote sensing imagery," Q. Tong, J. Shan, and B. Zhu, Eds., in Proceedings of the Remote Sensing of the Environment: 18th National Symposium on Remote Sensing of China, vol. 9158, Spie-Int Soc Optical Engineering, Bellingham, WA, USA, May 2014.

[57] B. Liu, W. Meng, J. Zhao, B. Hu, L. Liu, and F. Zhang, "Variation of coastline resources utilization in China from 1990 to 2013," Journal of Natural Resources, vol. 30, pp. 2033-2044, 2015.

[58] W. Sun, Y. Ma, J. Zhang, S. Liu, and G. Ren, "Study of remote sensing interpretation keys and extraction technique of different types of shoreline," Bulletin Survey Mapping, vol. 3, pp. 41-44, 2011.

[59] X. Hou, T. Wu, W. Hou, Q. Chen, Y. Wang, and L. Yu, "Characteristics of coastline changes in mainland China since the early 1940s," Science China Earth Sciences, vol. 59, no. 9, pp. 1791-1802, 2016.

[60] N. Xu, Research on Spatial and Temporal Variation of China Mainland Coastline and Coastal Engineering, Yantai Insititute of Coastal Zone Research CAS, Yantai, China, 2016.

[61] H. Tian, K. Xu, J. I. Goes, Q. Liu, H. D. R. Gomes, and M. Yang, "Shoreline changes along the coast of mainland China-time to pause and reflect?" ISPRS International Journal of Geo-Information, vol. 9, no. 10, p. 572, 2020.

[62] W. D. Thornbury, Principles of Geomorphology, John Wiley \& Sons, New York, NY, USA, 1969.

[63] M. Mishra, "Geomorphic regionalization of coastal zone using geospatial technology," International Journal of Environment and Geoinformatics, vol. 3, no. 2, pp. 11-23, 2016.

[64] C. Wen-Hung, H. Bin-Chen, and C. Piao-Tsai, "Simulation of shoreline change behind a submerged permeable breakwater," in Proceedings of the Taiwan-Polish Joint Seminar on Coastal Protection, Tainan, Taiwan, November 2008.

[65] D. B. King, "The dynamics of inlets and bays," Technical Report No. 2, Coastal and Oceanographic Engineering Laboratory, University of Florida, Gainesville, FL, USA, 1974.

[66] Q. Fan, L. Liang, F. Liang, and X. Sun, "Research progress on coastline change in China," Journal of Coastal Research, vol. 99, no. sp1, pp. 289-295, 2020.

[67] B. Ai, R. Zhang, H. Zhang, C. Ma, and F. Gu, "Dynamic process and artificial mechanism of coastline change in the Pearl River Estuary," Regional Studies in Marine Science, vol. 30, Article ID 100715, 2019.

[68] X. Ding, X. Shan, Y. Chen, X. Jin, and F. R. Muhammed, "Dynamics of shoreline and land reclamation from 1985 to 2015 in the Bohai Sea, China," Journal of Geographical Sciences, vol. 29, no. 12, pp. 2031-2046, 2019.

[69] M. S. Zhu, T. Sun, and D. D. Shao, "Impact of land reclamation on the evolution of shoreline change and nearshore vegetation distribution in Yangtze River Estuary," Wetlands, vol. 36, no. S1, pp. 11-17, 2016.

[70] X. Zhang, D. Pan, J. Chen, J. Zhao, Q. Zhu, and H. Huang, "Evalu0ation of coastline changes under human intervention using multi-temporal high-resolution images: a case study of the Zhoushan Islands, China," Remote Sensing, vol. 6, no. 10, pp. 9930-9950, 2014. 